San Jose State University

SJSU ScholarWorks

Master's Theses

Master's Theses and Graduate Research

1990

\title{
A comparison of short-term memory strategies in learning disabled students receiving special education services and learning disabled students who are no longer in need of special education services
}

Anne Legallet Jones

San Jose State University

Follow this and additional works at: https://scholarworks.sjsu.edu/etd_theses

Recommended Citation

Jones, Anne Legallet, "A comparison of short-term memory strategies in learning disabled students receiving special education services and learning disabled students who are no longer in need of special education services" (1990). Master's Theses. 3273.

DOI: https://doi.org/10.31979/etd.qa8w-wv6a

https://scholarworks.sjsu.edu/etd_theses/3273

This Thesis is brought to you for free and open access by the Master's Theses and Graduate Research at SJSU ScholarWorks. It has been accepted for inclusion in Master's Theses by an authorized administrator of SJSU ScholarWorks. For more information, please contact scholarworks@sjsu.edu. 


\section{INFORMATION TO USERS}

The most advanced technology has been used to photograph and reproduce this manuscript from the microfilm master. UMI films the text directly from the original or copy submitted. Thus, some thesis and dissertation copies are in typewriter face, while others may be from any type of computer printer.

The quality of this reproduction is dependent upon the quality of the copy submitted. Broken or indistinct print, colored or poor quality illustrations and photographs, print bleedthrough, substandard margins, and improper alignment can adversely affect reproduction.

In the unlikely event that the author did not send UMI a complete manuscript and there are missing pages, these will be noted. Also, if unauthorized copyright material had to be removed, a note will indicate the deletion.

Oversize materials (e.g., maps, drawings, charts) are reproduced by sectioning the original, beginning at the upper left-hand corner and continuing from left to right in equal sections with small overlaps. Each original is also photographed in one exposure and is included in reduced form at the back of the book.

Photographs included in the original manuscript have been reproduced xerographically in this copy. Higher quality $6 "$ x $9 "$ black and white photographic prints are available for any photographs or illustrations appearing in this copy for an additional charge. Contact UMI directly to order.

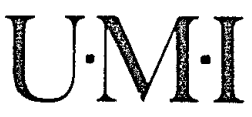

Universily Microlims International

A Bel! \& Howel! Intormalion Company

300 Norin Zeeb Road. Ann Arbor. MI 48106-1346 USA

$313761.4700 \quad 800521.0600$ 

Order Number 1340526

\begin{abstract}
A comparison of short-term memory strategies in learning disabled studente receiving special education services and learning disabled students who are no longer in need of special education services
\end{abstract}

Jones, Anne Legallet, M.A.

San Jose State University, 1990 

A COMPARISON OF SHORT-TERM MEMORY STRATEGIES IN LEARNING DISABLED STUDENTS RECEIVING SPECIAL EDUCATION SERVICES AND LEARNING DISABLED STUDENTS WHO ARE NO LONGER IN NEED OF SPECIAL EDUCATION SERVICES

\author{
A Thesis \\ Presented to \\ The Faculty of the Division of Special Education \\ and Rehabilitative Services \\ San Jose State University
}

In Partial Fulfillment

of the Requirements for the Degree Master of Arts

by

Anne Legallet Jones

May, 1990 
APPROVED FOR THE DIVISION OF SPECIAL EDUCATION AND REHABILITATIVE SERVICES

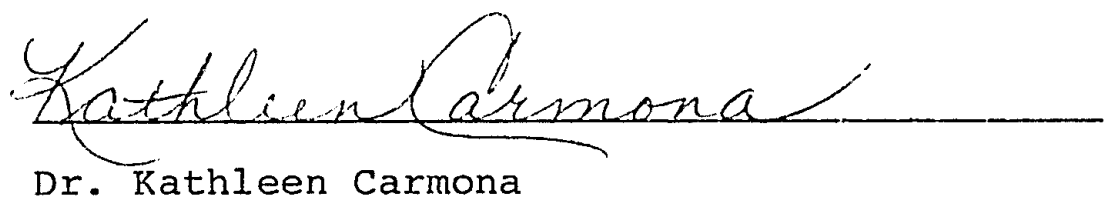

Dr. Kathleen Carmona

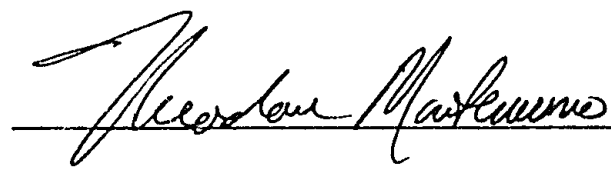

Dr. Theodore Montemurro

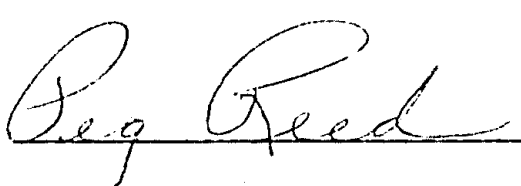

Ms. Peg Reed

APPROVED FOR THE UNIVERSITY

Th. Fou Sewandrush. 
ABSTRACT

A COMPARISON OF SHORT-TERM MEMORY STRATIEGIES IN LEARNING DISABLED STUDENTS RECEIVING SPECIAL EDUCATION SERVICES AND LEARNING DISABLED STUDENTS WHO ARE NO LONGER IN NEED OF SPECIAL EDUCATION SERVICES

by Anne Legallet Jones

This thesis examines differential use of cognitive strategies between learning disabled students receiving special education in a resource specialist program (RSP) and those no longer in need of special education (NRSP). Hagen's Central Learning Task was administered to the two groups of ten 12- to 13-year-old students. Students were required to find a specific animal among seven animal/ household object picture cards displayed and turned face down in a horizontal line. Proportion of correct responses was recorded at each serial position.

A two-way analysis of variance reveals significant effects for groups $[F(1,18)=4.645$, p.<.05] and serial position $[F(6,108)=3.811, p<.002]$. NRSP students did better than RSP students on Hagen's Central Learning Task. The pattern of correct responses at each serial position and posttest responses suggest that students in the NRSP group were more likely to use cognitive strategies to aid recall. This research demonstrates the need to explore cognitive strategy instruction for learning disabled students. 
TABLE OF CONTENTS

PAGE

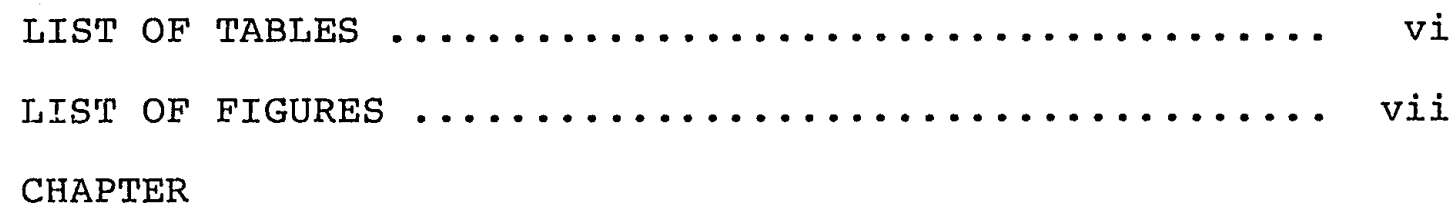

I INTRODUCTION $\ldots \ldots \ldots \ldots \ldots \ldots \ldots \ldots \ldots \ldots \ldots \ldots$

Statement of Research Problem ........... 6

Purpose of the study ................ 7

Hypothesis $\ldots \ldots \ldots \ldots \ldots \ldots \ldots \ldots \ldots \ldots \ldots$

Definition of Terms $\ldots \ldots \ldots \ldots \ldots \ldots \ldots$......... 8

Assumptions $\ldots \ldots \ldots \ldots \ldots \ldots \ldots \ldots \ldots \ldots$

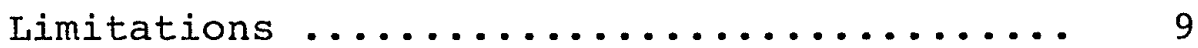

Delimitations ..................... 10

II REVIEW OF THE LITERATURE .............. 11

Learning Disabilities and Cognitive

strategies ...................... 11

Learning Disabilities and the Acquisition

of Cognitive Strategies ............ 16

Learning Disabilities and the Application

of Cognitive strategies ............ 19

summary $\ldots \ldots \ldots \ldots \ldots \ldots \ldots \ldots \ldots \ldots \ldots \ldots \ldots \ldots . \ldots \ldots$

III $\quad$ METHODOLOGY $\ldots \ldots \ldots \ldots \ldots \ldots \ldots \ldots \ldots \ldots \ldots \ldots$

Participants in Sample ................ 24

Research Sample ................... 25

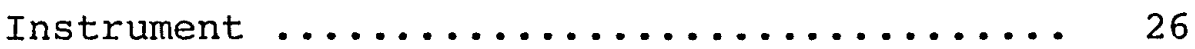


TABLE OF CONTENTS (Continued)

PAGE

Procedure $\ldots \ldots \ldots \ldots \ldots \ldots \ldots \ldots \ldots \ldots \ldots \ldots . \ldots \ldots$

Data Collection ....................... 29

Statistical Analysis ................ 29

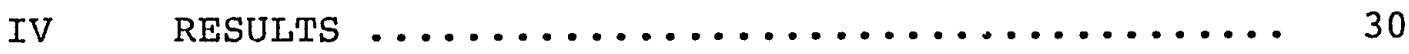

V. DISCUSSION, RECOMMENDATIONS, AND SUMMARY .... 36

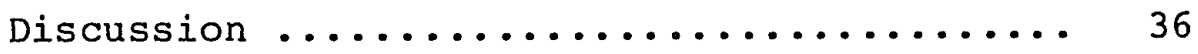

Implications for Instructing Learning

Disabled students ................ 39

Implications for Research ............ 42

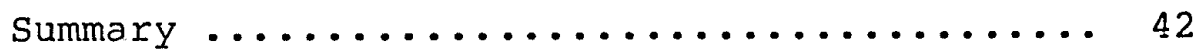

REFERENCES $\ldots \ldots \ldots \ldots \ldots \ldots \ldots \ldots \ldots \ldots \ldots \ldots \ldots \ldots \ldots \ldots$ 


\section{LIST OF TABLES}

PAGE

TABLE

1. Two-factor Analysis of Variance with

Repeated Measures .................... 34

2. Use of Verbalization and Visualization

Strategies by Groups ................. 35 


\section{LIST OF FIGURES}

PAGE

\section{FIGURE}

1. Mean proportion of correct responses by

groups as a function of serial position ...... 32

vii 
CHAPTER I

\section{INTRODUCTION}

Learning disabilities impede the acquisition of academic and social skills for many children. It has been estimated that $4.63 \%$ of the total number of children enrolled in school are learning disabled (U.S. Dept. of Education, 1984). Learning disabilities can affect children's ability to achieve in school and adjust to society. However, the term learning disabilities is one that cannot be clearly defined (Lerner, 1985). Although many definitions have been generated, each with its own shortcomings, the one most widely accepted reads:

Specific Learning Disability means a disorder in one or more of the basic psychological processes involved in understanding or in using spoken or written language, which may manifest itself in an imperfect ability to listen, think, speak, read, write, spell, or do mathematical calculations. The term includes such conditions as perceptual handicaps, brain injury, minimal brain dysfunction, dyslexia, and developmental aphasia. The terms does not include children who have learning problems which are primarily the result of visual, hearing, or motor handicaps, of mental retardation, or of environmental, cultural, or economic disadvantage. (PL-94-142, U.S. Office of Education; August 23, 1977) 
The operational part of this definition, used to identify such children in schools, states that a student has a specific learning disability if:

(1) the student does not achieve at the proper age and ability levels in one or more of several specific areas when provided with appropriate learning experiences and (2) the student has a severe discrepancy between achievement and intellectual ability in one or more of the following areas: (a) oral expression; (b) listening comprehension; (c) written expression; (d) basic reading skill; (e) reading comprehension; (f) mathematics calculation; (g) mathematics reasoning. (PL-94-142, U.S. Office of Education; August 23, 1977) Children identified as having learning disabilities by school personnel can generally be described by this definition.

Many theories have been developed to explain learning disabilities. Three such theories provide a framework for meeting the challenge of learning disabilities. They include: maturational, processing, and academic skills mastery theories.

Maturational theories suggest that a progression of abilities normally occurs under appropriate conditions. Maturational theorists propose that individuals with learning disabilities are more immature and poorly 
integrated than others at their age level (Koppitz, 1972).

Processing theories are based on the premise that certain students fail to learn efficiently in school because of deficits in such psychological processing functions as auditory or visual perception, cognition, and memory. Thus, processing theorists propose that individuals with learning disabilities experience disorders in the ways in which they organize and interpret data or stimuli (Johnson \& Myklebust, 1967; Kirk \& Chalfant, 1984).

Academic skills mastery theories hold that assessment should be restricted to the strengths and weaknesses of specific skills. Academic skills theorists do not acknowledge any special learning problems or ability deficits within the child other than lack of experience and practice with the task. The underlying assumption is that academj.c success or failure is due to the connections between subskills that are characteristic of a particular academic task (Ysseldyke, 1978).

These theories of learning disabilities are not mutually exclusive. Recently, there has been a movement towards more comprehensive theories that encompass aspects from maturational, processing, and academic skills mastery theories. The term cognitive strategies will be used to denote this group of theories. Like maturational theorists, cognitive strategy theorists acknowledge the development of cognition, the manner in which humans acquire, interpret, 
organize, store, retrieve, and employ information. Cognitive strategy theories include the concept that cognitive abilities develop at all stages of life and involve various kinds of behavior as the child matures. What students learn depends on their existing cognitive structure, the experience, and the knowledge that they bring to the learning situation (Piaget, 1970). Similar to processing theories, they are based on the knowledge that learning disabled children do poorly on tasks designed to measure attention, short-term memory, various perceptual skills, ability to integrate stimuli from different sensory modalities and many other psychological functions (Heinicke, 1972; Torgeson, 1975). Finally, cognitive strategy theories also utilize the idea from academic skills mastery theories that low performance of learning disabled children on tasks that attempt to measure these psychological functions or academic knowledge may be attributable to failure to employ efficient, active, and successful strategies on these tasks rather than to ability deficits (Torgeson, 1977a). These comprehensive theories suggest that learning disabled children of all ages often do not spontaneously use appropriate task strategies in a variety of situations (Hallahan \& Reeve, 1980; Torgeson, 1977b). In essence, cognitive strategy theories describe the way learning disabled children approach a learning situation. The body of evidence that supports the 
suggestion that learning disabled children do not use efficient cognitive strategies to learn and comprehend information has been drawn from research on two essential components of learning: attention and memory (Belmont \& Butterfield, 1971; Tarver, Hallahan, Cohen, \& Kauffman, 1977; Torgeson, 1977a, 1977b). Thus, to study the nature of the learning disabled child's use of efficient cognitive strategies in various learning situations, researchers have broken the complex action of learning into two processes that are behaviorally observable. From this perspective, the cognitive strategies that learning disabled children fail to apply in learning are those that aid attention to and recall of information to be learned.

In accordance with cognitive strategy theories, it has been shown that directly training learning disabled children to utilize cognitive strategies efficiently increases their performance on various cognitive tasks (Torgeson, 1980). Furthermore, instruction in the use of cognitive strategies has been found to affect achievement positively, particularly in the area of reading (Clark, Deschler, Schumaker, \& Alley, 1984; Rose, Cudick, \& Higbee, 1983). Therefore, teaching learning disabled children to use efficient cognitive strategies may aid their performance on cognitive tasks and academic achievement. Additionally, it has been recognized that not all learning disabled children fail to employ strategies when given the opportunity 
(Torgeson, Murphy, \& Ivey, 1979). This evidence, combined with the fact that some learning disabled children do graduate from special education classes, points to the question of whether these students who are independently achieving at a normal level use more efficient cognitive strategies than do learning disabled children who remain in special education classes. This research examined differential use of cognitive strategies between learning disabled children who were currently receiving special education and those who were able to function without special education in a regular classroom environment. Statement of Research Problem

Evidence shows that learning disabled children use inefficient cognitive strategies in a variety of situations, resulting in failure to perform normally on cognitive tasks. The difficulty is confounded when this failure manifests itself in poor academic achievement. The problem is particularly apparent when it affects the child's ability to reach his or her full potential in areas of academic and daily life.

Efficient use of cognitive strategies when approaching learning tasks may be viewed as a variable that affects the ability of learning disabled children to achieve. It may be a factor keeping these children from doing as well as they could in school. Previous research has demonstrated that direct instruction in use of cognitive strategies increases 
learning disabled children's performance on cognitive and academic tasks (Rose, Cudick \& Higbee, 1983; Torgeson, 1977b). Furthermore, some learning disabled children are able to achieve at normal levels after special education. This suggests a qualitative difference between learning disabled children who need special education and those who are able to function at appropriate academic and social levels, independent of special education. Efficient use of cognitive strategies in learning situations may be a factor that contributes to that qualitative difference, thereby allowing some learning disabled children to succeed in a regular classroom environment while others remain in special education classes.

Purpose of study

The purpose of the study is to find a differential variable between learning disabled students who require special education and those who have successfully exited special education and are able to function independently in the mainstream.

Hypothesis

It is hypothesized that the mean proportion of correct first responses of learning disabled students who have graduated from special education programs on Hagen's Central Learning lask will be significantly greater than will the mean proportion of correct responses of learning disabled students who are receiving special education. 
Definition of Terms

Learning disabled child. A student who is identified by school personnel as having specific learning disabilities.

Learning. The process of gaining knowledge, comprehension, or mastery through experience or study.

Cognitive task. A goal-directed activity requiring the mental manipulation of stimuli to accomplish it.

Central learning task. A goal-directed activity in which the specific direction of learning is identified.

Incidental learning task. A goal-directed activity in which the knowledge to be learned is not previously identified.

Efficient. cognitive strategies. The use of internal thinking processes to correctly recall or comprehend information to be learned.

Categorization. The cognitive strategy of combining stimuli into meaningful groups to aid recall or comprehension.

Labeling. The cognitive strategy of giving stimuli meaningful names to aid recall or comprehension.

Verbal rehearsal. The cognitive strategy of repeating labels for stimuli to aid recall or comprehension. Visual imagery. The cognitive strategy of making mental pictures of stimuli to aid recall or comprehension. Normal academic achievement. Indicated by academic 
test scores and grades not significantly lower than those of individuals at the same age level with similar levels of intelligence.

Mainstreaming. Placing of children with handicaps within the regular education system of the school, particularly in the regular classroom.

Primacy effect. The correct recall of information at the beginning positions of a serial recall task.

Recency effect. The correct recall of information at the final positions of a serial recall task. Assumptions

For purposes of this research, it is assumed:

1. The children observed within this study have been correctly diagnosed as having specific learning disabilities by school personnel.

2. Children who have graduated from learning handicapped special education programs are achieving at a level appropriate for their grade placement.

3. A child who correctly responds to Hagen's Central Learning Task has made use of efficient cognitive strategies.

\section{Iimitations}

The researcher acknowledges the following limitations:

1. Short-term variables may affect responses to Hagen's Central Learning Task at the time it is given. For example, situational events at home or school may affect the 
child's ability to respond correctly at that time.

2. In using the proportion of correct responses to Hagen's Central Learning Task as a measure of use of efficient cognitive strategies, covert cognitive strategies are not directly evaluated. Use of efficient cognitive strategies is assumed from recall and the serial position of correct responses.

3. The previous educational backgrounds of the children will not be known. Thus, methods of past instruction or strategies used by teachers to help the children learn will be ignored. Delimitations

For the purpose of conducting this research, the researcher will impose the following delimitations:

1. Only one test that attempts to measure the children's use of efficient cognitive strategies will be utilized.

2. The researcher will administer Hagen's Central Learning Task to those children previously identified as learning disabled within one age group.

3. The processing problem associated with learning disabilities will not be considered as a variable affecting use of cognitive strategies.

4. The children will be from schools within the boundaries of the selected elementary school districts. 
CHAPTER II

\section{REVIEW OF THE LITERATURE}

Some research supports the hypothesis that learning disabled children use less efficient strategies on cognitive tasks than do non-learning disabled children. Additionally, it has been determined that some learning disabled children improve on cognitive and academic tasks after they have been instructed in the use of cognitive strategies. Furthermore, it is known that some learning disabled children are able to achieve at normal academic levels after receiving remediation in special education classes.

This literature review first explores the nature of cognitive strategies employed by learning disabled children, particularly in comparison with non-learning disabled children. It then reviews studies providing evidence that the performance of learning disabled children will improve on selective attention, memory, and other cognitive tasks after they have been instructed in the use of cognitive strategies. Finally, this chapter examines research surrounding the relationship between the use of cognitive strategies by learning disabled children and their academic achievement.

Learning Disabilities and Cognitive Strategies

Research that explores the use of cognitive strategies by learning disabled children has focused primarily on the two processing systems of attention and memory. Both of 
these systems provide a concrete way of reporting results in the form of recall of information presented. Cognitive strategies needed to perform selective attention and memory tasks have provided the most significant descriptions of how learning disabled children approach these tasks in comparison with non-learning disabled children.

Selective attention. Selective attention is defined as "the ability to attend to relevant (central) information in the face of irrelevant (incidental) information" (Lerner, 1985, p. 209). Many researchers see attention deficits as the most critical defect of the learning disabled student (Dykman, Ackerman, \& Olglesby, 1980; Hallahan \& Reeve, 1980; Hallahan \& Sapona, 1983). Thus, researchers have a basis for their interest in examining how learning disabled children approach these cognitive tasks. Their studies have shown that learning disabled children often do not use efficient encoding strategies such as labeling and verbal rehearsal. For example, Tarver, Hallahan, Cohen, and Kauffman (1977) presented 8-, 10-, and 13-year-old learning disabled boys with a task that required them to examine a series of seven picture cards that contained a black outlined drawing of an animal on the lower half and a household object on the upper half. After an observation period, the cards were turned over and the children were shown a probe card of an animal previously displayed. The boys were then asked where the picture of that animal was 
among the seven cards. Upon comparing the responses of the subjects to those of non-learning disabled children of the same age, the researchers found that learning disabled children failed to recall items earlier in the series (primacy effect). Previous research that supported the correlation between verbal rehearsal and the primacy effect in responses of mentally retarded children (Belmont \& Butterfield, 1971; Ellis, 1970) allowed the investigators to conclude that the learning disabled children did not use verbal rehearsal to aid recall. An earlier study by Tarver, Hallahan, Kauffman, and Ball (1976) also supported this conclusion.

In further describing results of research on the selective attention of learning disabled children, Brown and Quay (1977) acknowledged that the attentional deficit is accompanied by a tendency to make decisions too rapidly and not to consider possible alternatives. Similarly, Hallahan and Reeve (1980) summarized studies on the selective attention of learning disabled children by stating, "It is not so much the learning disabled child's inability to attend selectively that is his basic problem so much as it is his inability to analyze the task in terms of the best strategies needed for performing it" (p. 156). These researchers suggest that learning disabled children approach tasks without a strategy. Therefore, research in the area of selective 
attention provides evidence for such qualitative differences as initial task approach and use of labeling or verbal rehearsal in the way learning disabled children undertake a cognitive task.

Memory. Memory pertains to the ability to store and retrieve previously experienced sensations and perceptions when the stimulus that originally evoked them is no longer present (Lerner, 1985). Learning disabled children have often been found to have difficulty performing on tests of memory (Howe, 1970). Thus, cognitive strategies used by learning and non-learning disabled children on memory tasks have become a pertinent way of understanding children's difficulty with such tasks. Studies focusing on the memory of learning disabled children differ from those on selective attention primarily in that recall is assessed without distracting variables. Research in the area of memory, similar to and sometimes overlapping with that of selective attention, has also demonstrated that learning disabled children do not use such strategies as verbal rehearsal, labeling, and categorization to aid recall. Many of these studies have used disabled readers with normal intelligence as subjects. For example, Torgeson (1977b) found that a sample of fourth grade disabled readers used inefficient strategies on two different kinds of memory tasks. On one of the tasks, study behaviors were examined as the children prepared to recall 24 pictures of common objects that 
could be grouped into four conceptual categories. Significant differences in recall between good and poor readers were accompanied by important differences in study strategies. With the experimenter out of the room during the study period, the good readers moved the pictures around more, verbalized the picture names more, and showed less off-task behavior. The good readers also showed more of a tendency to categorize the pictures into conceptual groups during the study period. The other task required children to study a horizontal array of pictures to be recalled in a left-to-right order. The pictures could be viewed one at a time by pressing a button that illuminated boxes containing the pictures. During a study period, both patterns of button presses and the subjects' verbal behavior were recorded. The major observational findings indicated differences in recall associated with more verbalization of the stimulus names by good readers. The pattern of button presses also indicated that the good readers engaged in more chunking and rehearsal of the stimuli. Similar studies using identified learning and reading disabled children as subjects also reported significant differences between learning and non-learning disabled children in the uses of categorization, labeling, and verbal rehearsal on these memory tasks (Torgeson \& Goldman, 1977; Torgeson \& Houck, 1980; Torgeson, Murphy, \& Ivey, 1979; Wong, Wong, \& Foth, $1977)$. 
Research on the use of cognitive strategies that focuses on selective attention and memory has folnd a lack of categorization, labeling, and verbal rehearsal employed by learning disabled children to aid in recalling information. Furthermore, learning disabled children have been described as making decisions too rapidly and failing to pause to consider possible alternatives. Learning Disabilities and the Acquisition of Cognitive strategies

The previous section reviewed the use of cognitive strategies employed by learning disabled children and also provided a framework for the question of whether learning disabled children have the capacity to acquire the cognitive strategies that they appear to be lacking. Two types of studies provide evidence that learning disabled children can learn to use cognitive strategies to increase their performance on cognitive tasks. This research includes the effects of incentives on efficient use of cognitive strategies and the results on performance of directly teaching cognitive strategies.

Incentives. Research examining the effect of positive reinforcement on the use of cognitive strategies by learning disabled children has suggested that reinforcement leads to the use of more efficient strategies. Hallahan, Tarver, Kauffman, and Graybeal (1978) tested the effects of two 
different kinds of incentives on the selective attention of learning disabled children. These researchers gave 48 learning disabled subjects a test of finding a probe animal or household object among a series of 15 previously shown picture cards. Subjects in the reinforcement group received pennies for each correct response. Subjects in the response cost group received 60 cents at the beginning of the session and pennies were taken away for incorrect responses. In the control group, subjects earned pennies for each answer, whether or not it was correct. The results indicated that giving money increased the selective attention of learning disabled children. After examining the pattern of recall for the primacy effect, researchers concluded that the group that was reinforced for recall had better selective attention due to the adoption of a verbal rehearsal strategy

Similarly, Haines and Torgeson (1979) also found that second grade learning disabled children with reading problems rehearsed more when they were rewarded for recall than when they were not. These findings imply that incentives either induced the learning disabled children to apply a strategy that was already in their repertoire or that it led to the development of a new strategy. Although other studies have found no significant differences between the use of incentives and the increase of verbal rehearsal (Dawson, Hallahan, Reeve, \& Ball, 1980; Hallahan et al., 
1978), the research does provide evidence that learning disabled children have the capacity to use cognitive strategies such as verbal rehearsal.

Instruction. Direct instruction of cognitive strategies such as verbal mediation and categorization have been found to improve the performance of learning disabled children on selective attention and memory tasks. Tarver et al. (1976) presented 18 learning disabled boys and 18 non-learning disabled boys at 10- and 13-year-old age levels with the task of recalling a series of seven animal pictures. In the standard condition, the task was administered with basic instructions. In the verbal rehearsal condition, the children vere required to label, categorize, and rehearse items verbally. After analyzing the responses of all four groups, the researchers found that a developmental lag of about two years was characteristic of the learning disabled group and that the selective attention of learning disabled children was significantly improved after instruction. Dawson, Hallahan, Reeve, and Ball (1980) also arrived at the same conclusion in their similar study. Additionally; Torgeson (1977b) found that briefly training fourth grade disabled readers in the use of categorization as a mnemonic strategy eliminated differences in recall between them and children reading at a normal level with similar intelligence quotients.

Recently, Feuerstein (1980) has examined the effects of 
teaching cognitive strategies to learning disabled children in a broader context than in previously cited studies. Feuerstein developed a teaching method called Instrumental Enrichment. In essence, this method teaches children to $\mathrm{plan}$ and organize internal strategies to solve problems verbally and then apply them to learning situations in their lives. Several research reports have indicated Instrumental Enrichment is effective in improving the problem-solving behavior of learning disabled children (Harth, 1982; Messerer, Hunt, Meyers, \& Lerner, 1984). Thus, instruction in strategies to aid attention and recall, as well as to organize thought, has been found to help learning disabled children in their performance on cognitive tasks.

Learning Disabilities and the Application of

\section{Cognitive Strategies}

Evidence suggests that learning disabled children can be taught to utilize cognitive strategies to approach cognitive tasks such as memory and problem-solving. A pertinent corollary assumption is that instruction in cognitive strategies can improve the academic achievement of learning disabled children. Research findings show that it does.

Rose, Cudick, and Higbee (1983) compared the effects of verbal rehearsal, visual imagery, and unaided instruction of cognitive strategies on reading comprehension of 30 learning 
disabled children. In the unaided treatment group, children were directed to read a story and remember as much as possible. In the verbal rehearsal condition, children were instructed to talk to themselves about what they were reading. Examiners modeled the strategy and then guided the children to use it. In the visual imagery condition, the children were told to pause, close their eyes, and make a picture or movie in their minds at certain intervals about what they were reading. The examiners guided the children in making internal visual pictures before they read. It was Eound that both verbal rehearsal and visual imagery significantly increased reading comprehension performance. Additionally, the largest gains were made by children in the verbal rehearsal condition.

Similarly, Clark, Deschler, Schumaker, and Alley (1984) instructed six. children in the use of self-questioning and categorization strategies. They found that scores on the Gilmore Reading Test improved significantly after intervention. Wong (1980) found that such training increased both reading comprehension and retention. Other research has indicated that teaching children such cognitive strategies as scanning, categorization, and verbalization increase performance on measures of reading and that the effects continue for at least three months (Brown \& Alford, 1984; Egeland, 1974).

In a different achievement area, Maier (1980) taught 
32 learning disabled children to categorize verbally parts of a story that was read to them. Another group of 32 children received no such instruction. After children were asked to remember and retell as much of the story as possible, a language sample revealed that there was a significant difference between the cognitive responses of the control and experimental groups. The children who had received instruction demonstrated a greater understanding of what they heard.

Cognitive strategy training has also been used in the area of written language. In a study designed to determine the efficacy of a memory strategy for eliminating writing reversal behavior, Mather and Healy (1985) reported that it is possible to reduce symbolic directional confusion by providing a learning disabled child with a verbal rehearsal strategy for remembering the directional orientation of the letters. Additionally, Graham and Freeman (1985) found that fourth grade learning disabled students who had been taught a five-step strategy to remember spelling words obtained significantly higher spelling scores than did learning disabled students who were not trained. They concluded that, once strategy training has been provided, studentcontrolled usage of the strategy can be as effective as teacher-monitored or teacher-controlled strategy usage in terms of recall performance.

In the achievement area of mathematics, the teaching of 
verbal labeling and self-questioning techniques was found to be effective in helping learning disabled students learn to solve mathematical problems (Carpenter, Moser, \& Rombers, 1982; Resnick \& Ford, 1981). Schunk and Cox (1986) investigated how verbalization of subtraction with regrouping operations influenced the self-efficacy and skillful performance of 11- to 14-year-old learning disabled students. In one condition, students received training in verbalizing aloud while solving problems during all sessions. In another condition, students received training in verbalization only during the first half of the problem solving sessions and in a third condition, students did not verbalize in any sessions. They found that continuous verbalization training led to higher self-efficacy and skillful performance than did discontinued and no verbalization training. All students who received strategy training were able to solve subtraction problems more rapidly and accurately than were students who did not receive training.

The studies reviewed in the area of teaching cognitive strategies to learning disabled children revealed increases in performance in the areas of reading, listening, writing, and mathematics. This research acknowledges that learning disabled children have the capacity to acquire and use cognitive strategies and apply them in areas of academic achievement. The purpose of this research will be to find a differential variable between learning disabled children 
who require special education and those who have successfully exited special education and are able to function in the mainstream.

Summary

There is evidence that learning disabled children do not spontaneously use verbal rehearsal, labeling, and categorization strategies on cognitive selective attention, memory, and problem-solving tasks. Furthermore, it has been found that using incentives sometimes increases the use of these strategies by learning disabled children and that instruction in their use can improve performance on cognitive tasks. These findings suggest that learning disabled children have the capacity to acquire and use cognitive strategies that were not previously in their repertoire. Most relevant is the finding that instruction in the use of cognitive strategies, particularly verbal rehearsal, significantly improves reading, writing, and mathematics achievement scores. Thus, it has been demonstrated that learning disabled children often do not use cognitive strategies in various situations and this may negatively affect academic achievement. However, these children can acquire strategies needed to perform essential cognitive tasks for learning and, therefore, achieve at a higher level. Cognitive strategies may then be viewed as variables affecting the academic performance of learning disabled children. 
CHAPTER III

METHODOLOGY

There has been evidence supporting the hypothesis that learning disabled children use less efficient strategies on cognitive tasks than do non-learning disabled children. Additionally, it has been determined that some learning disabled children improve on cognitive and academic tasks after they have been instructed in the use of cognitive strategies. Furthermore, it is known that some learning disabled children are able to achieve at normal academic levels after receiving remediation in special education classes. This researcher used Hagen's Central Learning Task to assess efficient use of cognitive strategies by 12- to 13-year-old learning disabled children who were still receiving special education and an equal number of children who had graduated from learning handicapped special education programs. It was hypothesized that the mean proportion of correct responses on Hagen's Central Learning Task by learning disabled children who are no longer in need of special education services would be significantly higher than would the mean proportion of correct responses of children receiving special education services in an RSP program.

\section{Participants in Sample}

Learning disabled children receiving special education in selected Middle School Resource Specialist Programs in the San Francisco Bay Area were participants in this study. 
Names of these children and children who had been released from these programs were obtained from school psychologists. These children were in a classroom with not more than seven other children for individualized instruction by a special education resource specialist for one or two hours of their school day. Those subjects not receiving special education had, at one time in their education, been identified as having specific learning disabilities but they were, at the time of this study, able to function normally in a regular classroom without special assistance by qualified school personnel. The selected elementary school districts used in this study were characterized by a wide range of socioeconomic and ethnic backgrounds. Research Sample

Learning disabled children between the ages of 12 and 13 were selected for this study from two populations of learning disabled children. One population included learning disabled children in special education classes and the other population included learning disabled students who had successfully exited special education. The research sample was further specified in that the 12- to 13-year-old learning disabled children receiving special education were matched with those not receiving special education on the basis of intelligence quotients. Thus, only children with total intelligence quotients between 95 and 110 were selected. The purpose of this specification was to hold the 
variable of IQ within the limits of one standard deviation of the distribution of individual intelligence scores. Use of cognitive strategies then would not be differentiated by a variability in intelligence quotients between the two groups.

The final 15 from a total of 28 names of children receiving special education and the 15 from a total of 26 names of children not receiving assistance were then put into bowls. Ten names from each bowl were drawn randomly for use in this research.

Instrument

Hagen's Central Learning Task (Hagen, 1967) was employed in this research to assess the use of cognitive strategies by 12- to 13-year-old learning disabled children. The strategies of labeling and verbal rehearsal were particularly emphasized in this assessment. In general, the task required the students to examine a series of seven cards which contained an animal outline on the lower half of each card and a household object on the upper half. After a period of observation, the cards were turned over and the student was shown a picture of one of the animals portrayed on one of the seven cards. The student was then asked to choose the card with the matching picture of that animal. This task has been used by several researchers who found significant differences in the mean proportion of correct responses between groups of learning disabled and 
non-learning disabled children (Dawson, Hallahan, Reeve, \& Ball, 1980; Donaldson \& Strang, 1969; Tarver et al., 1976). These researchers also found that learning disabled children forgot items presented early in a series more than non-learning disabled children did. These patterns of responses, direct observation, and questioning led researchers to conclude that learning disabled children did not label or use verbal rehearsal as much as did non-learning disabled children. The findings from previous research suggest that Hagen's Central Learning Task is a valid and reliable way to assess the use of cognitive strategies by learning disabled children to recall previously observed stimuli.

Procedure

Students were individually administered Hagen's Central Learning Task in a small, quiet classroom area. Testing took place at various times during each students' school day. The task was administered by a Resource specialist in a single session lasting approximately 20 minutes. Central test stimuli, similar to those originally devised by Hagen (1967), consisted of seven $5 \times 3$-inch white cards, each of which contained two 3 x 3-inch black line drawings: an animal picture on the lower half and a familiar object picture on the upper half. The same animal and object were always paired together. Students were instructed to pay attention to the animals. Fourteen 7-item test trials were 
administered with each item being presented for 2 seconds and then turned face down to form a horizontal row. Immediately following presentation of the last item in each series, a 3 x 3-inch probe card containing only an animal. picture was presented and the student was asked to turn over the test card containing the animal picture identical to the one on the probe card. Only the first responses were recorded; however, in the case of an incorrect first response, the student was allowed to continue to respond until he chose the correct card. The stimulus cards were presented in random order, with the restrictions that each of the seven animals and each of the seven serial positions were probed twice during the 14 trials. To control for fatigue effects, the order of presentation of the 14 seven-item series was counterbalanced. Therefore, within each group of subjects, the first child began with series 1 and ended with series 14 , the second child began with series 2 and ended with series 1 , and so on. The proportion of correct first responses on the 14 trials constituted each child's central recall score.

Immediately following completion of the central recall phase of the task, the examiner questioned each subject on the method used to remember where the animal was in the series. The following inquiries were made:

a. Did you tell yourself what the name of the arimal was in each picture? 
b. Did you repeat the name of the animal in your head to remember?

c. Did you try to see the picture of the animal in your head when it was shown to you?

d. Did you imagine the animal on the back of the cards or in your head when you were trying to remember where the animal was in the row?

Data Collection

Data were collected for each child by marking the serial position ( 1 to 7 from the left) of each correct response for each of the 14 trials. The students' responses to the strategy inquiries were recorded verbatim by the Resource Specialist who conducted the test. Statistical Analysis

The mean proportion of correct responses at each serial position was calculated for each child. A two-way analysis of variance was applied. Thus, comparisons were made between groups (those in special education and those graduated from special education) in mean proportion of correct recall, serial position of correct responses, and the interaction between the two. 
CHAPTER IV

\section{RESULTS}

This study compared the use of cognitive strategies by two groups of 12- to 13-year-old learning disabled students. One group was receiving special education in a Resource Specialist Program (RSP) and the other group had graduated from a.Resource Specialist Program (NRSP). All of the students had intelligence quotients between 95 and 110. The ten students in the RSP group were achieving significantly below their intellectual potential in one or more academic areas. The ten students in the NRSP group were achieving according to their intellectual potentials in all academic areas and were able to function in the mainstream without support from a Resource Specialist.

The Hagen's Central Learning Task (Hagen, 1967) was administered to both groups of learning disabled students. The task measures the student's use of cognitive strategies on a serial activity involving both central and incidental visual stimuli. The students were asked to find a specific animal among seven animal/household object picture cards that had been shown to them and turned over one-at-a-time in a line in front of them. The student's first responses were recorded. The mean proportion of correct responses, the serial location of correct responses and the interaction between both were compared between and within the two groups. 
As depicted in Figure 1, central recall of learning disabled students in the NRSP group was greater than that cf learning disabled children in the RSP group. Out of a total of 20 possible correct responses at each position for each group, the NRSP group chose the correct animal more often in positions $1,2,3,4,5$ and 6 . Only in serial position 7 did the RSP group have a greater proportion of correct responses.

Within groups, students in the NRSP group had a greater proportion of correct responses at position 1 than at position 7 . This suggests a primacy effect. Students in this group were more likely to remember animals that they saw first in the series of cards. Positions 1 and 3 had the greatest proportion of correct responses for the NRSP group.

Students in the RSP group had a greater proportion of correct responses at position 7 than at positions $1,2,3,4,5$ and 6. The lowest proportion of correct responses was at position 6. There was a .55 increase in mean proportion of correct responses from position 6 to position 7 for this group. This suggests a recency effect. Students in this group were more likely to remember animals that they saw at the end of the series of 7 cards.

The hypothesis posed in this study was that the mean proportion of correct responses on Hagen's Central Learning Task would be significantly greater for learning disabled students who had graduated from special education programs 
Figure 1. Mean proportion of correct responses by groups as a function of serial position.

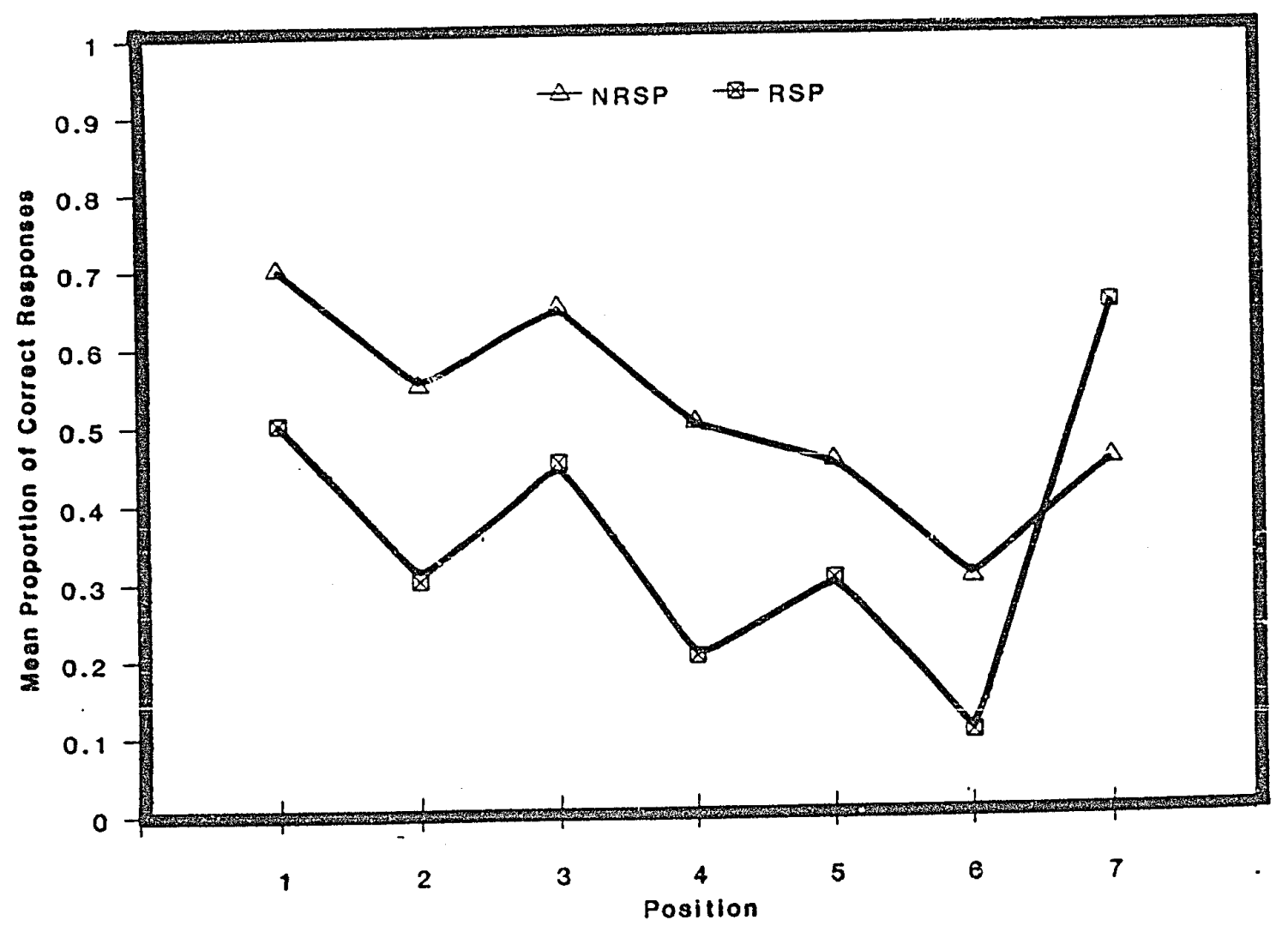


than for learning disabled students receiving special education. To test the hypothesis, results of a group (learning disabled in RSP versus learning disabled graduated from RSP) by serial position ( 1 - 7) two-way analysis of variance with repeated measures for positions for central recall was conducted. Results are reported in Table 1. The data suggest significant effects for groups $[F(1,18)=4.645, p<.05]$ and for serial position $[F(6,108)=3.811, p<.002]$. The hypothesis was accepted.

Each participant in the study was also asked a series of questions about a method they have used to remember where the animal was in the series of 7 cards. Two categories of questions were posed: verbalization and visualization.

The verbalization questions posed were:

1. Did you tell yourself what the name of the animal was in each picture?

2. Did you repeat the name of the animal in your head to remember?

The visualization questions posed were:

1. Did you try to see the picture of the animal in your head when it was shown to you?

2. Did you imagine the animals on the back of the cards or in your head when you were trying to remember where the animal was in the row? 
Table 1

Two-factor Analysis of Variance with Repeated Measures

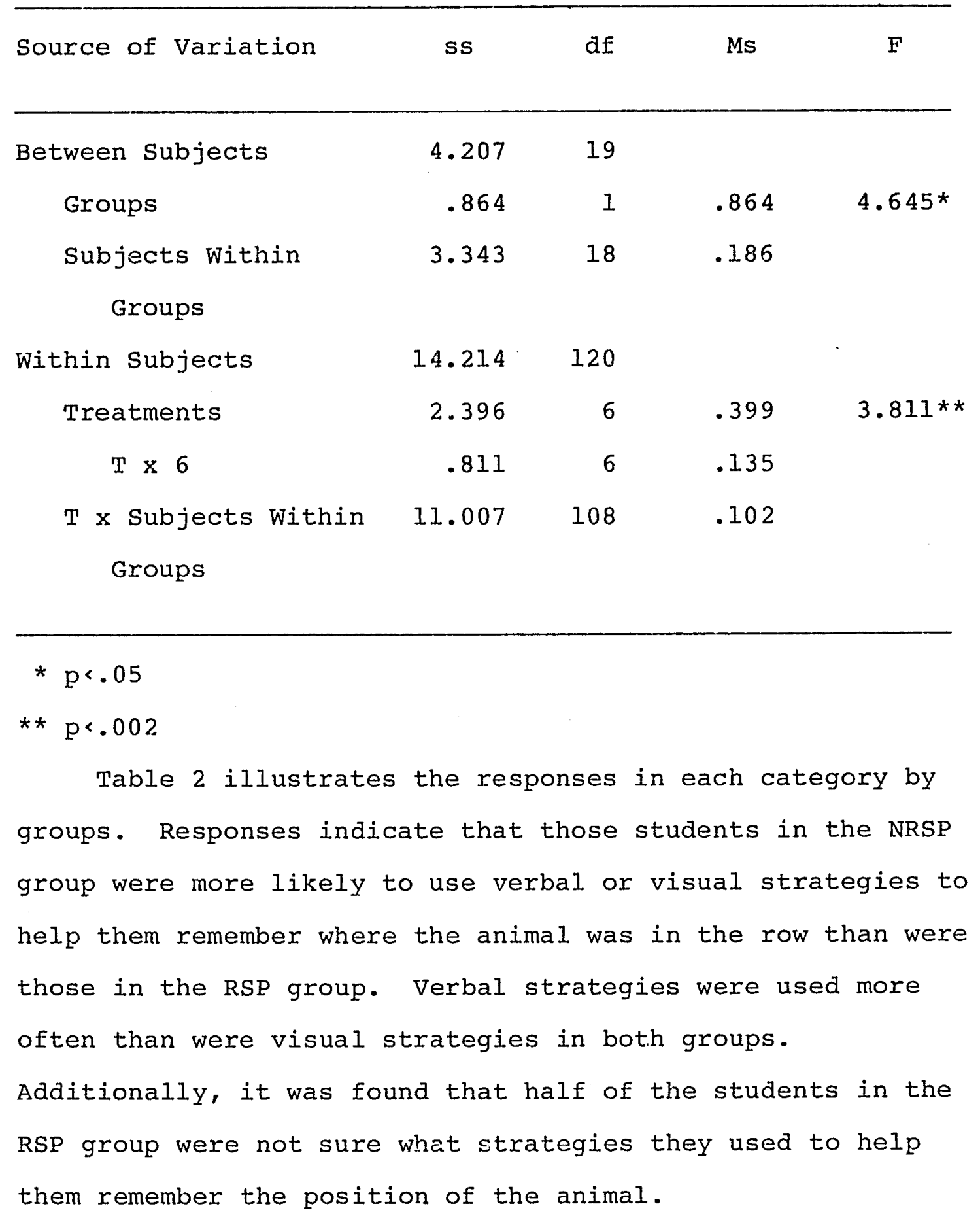


Table 2

Use of Verbalization and Visualization Strategies by Groups

\begin{tabular}{lcccc} 
& Verbal & Visual & Both & Not Sure \\
\hline NRSP & 6 & 1 & 1 & 2 \\
RSP & 4 & 1 & 0 & 5 \\
\hline
\end{tabular}




\section{CHAPTER V \\ DISCUSSION, RECOMMENDATIONS, AND SUMMARY}

\section{Discussion}

The results of this study indicate that $12-$ to 13-year-old learning disabled students who had graduated from a Resource Specialist Program (NRSP) scored higher on Hagen's Central Learning Task, a selective attention activity requiring them to recall an animal outline in a series of seven cards, than did 12- to 13-year-old learning disabled students who were currently enrolled in a Resource Specialist Program (RSP). A significant relationship between the serial positior of the animal card to be remembered and the proportion of correct responses was also found.

The NRSP group attained a greater proportion of correct responses at position 1 of the series than at position 7 . This indicates that students in the NRSP group were more likely to recall the animal that they saw first. It was only at the last serial position that the proportion of correct responses was greater in the RSP group. The RSP group recalled more items at position 7 of the series than at position 1. Dawson et al. (1979), Donaldson et al. (1969), and Tarver et al. (1976) obtained similar results in their studies comparing groups of learning disabled with non-learning disabled students on Hagen's Central Learning Task. They found that groups of non-learning disabled 
students had better recall on the task and that they had a greater proportion of correct responses at position 1 of the series. They labeled this pattern primacy effect and concluded that these students were using a verbal rehearsal strategy to help them remember. They also determined that the learning disabled group was not using a verbal rehearsal strategy because the proportion of their correct responses at each position suggested a small or no primacy effect and demonstrated a more pronounced recency effect. In the recency effect, there was a greater proportion of correct responses at the end of the series. This response pattern was similar to the one exhibited by the RSP group in the present study. The results of these past studies, when examined with the present study comparing NRSP and RSP groups on Hagen's Central Learning Task, support the deduction that students in the NRSP group were more likely to use cognitive strategies to aid recall than were students in the RSP group. This deduction is further sustained by posttest questions that revealed $80 \%$ of the NRSP students reported using a verbal, visual, or combination strategy to aid recall while $50 \%$ of the RSP students reported that they used either a verbal or visual strategy.

Previous studies found that learning disabled students can learn cognitive strategies. Hallahan et al., (1978) and Haines et al. (1979) found that learning disabled children 
who were directly taught strategies such as labeling, categorizing, or verbal rehearsal improved selective attention and recall. Therefore, it is possible that students in the NRSP group of the present study learned to utilize efficient cognitive strategies and, therefore, were able to obtain a greater proportion of correct responses on Hagen's Central Learning Task. Developmentally, the students in the NRSP and RSP groups were at the same age level and had scored within the same range on intelligence tests. Thus, a qualitative difference between the two groups may be that the NRSP students had learned to use more efficient cognitive strategies to aid recall than had those students who had remained in RSP.

This study goes beyond the research that has found that incentive based or direct instruction of cognitive strategies improves achievement in academic areas. It focuses on a possible discriminating factor between two groups of learning disabled students who were at the same age and intellectual level but differed in their need for special education. The NRSP students in this study had all been released from receiving direct, daily help from a resource specialist. Resource specialists determined that these students were capable of performing adequately in regular classrooms. The students in the RSP group were evaluated by their resource specialists by achieving significantly below their intellectual potentials. They 
were not capable of functioning adequately in regular classrooms. They needed daily support from special education. Research has shown that learning disabled students can learn to use cognitive strategies to help them in reading comprehension (Clark et al., 1984; Maier, 1980 ; Rose et al., 1983), writing (Mather \& Healy, 1985), and mathematics (Resnick \& Ford, 1981; Schunk \& Cox, 1986). Thus, it is feasible that students in the NRSP group had developed the ability to use cognitive strategies efficiently to recall the position of an animal card in a series of seven and also function adequately in the mainstream without special education. The results of this study point toward a need for special education teachers to focus on student acquisition of cognitive strategies. The suggested relationship between efficient use of cognitive strategies and achievement in the NRSP group has important implications for teaching learning disabled students and identifies a need for future research in this area. Implications for Instructing Learning Disabled Students

An inherent goal of special education is that students will ultimately be able to achieve at a level consistent with their intellectual functioning in all academic areas. At this point, students would not require special education. In the present study, the NRSP students had attained this goal. They were also using more cognitive strategies than were learning disabled students at the same age and 
intellectual level who had not attained this goal. Therefore, it is suggested that directly teaching or including cognitive strategies as part of a Resource Specialist Program curriculum may help students function independently in the mainstream.

Methods for teaching cognitive strategies can be divided into two general categories. In one type of instruction, students are taught strategies to help them complete various problem solving activities. The other instructional method involves the direct instruction of strategies as they apply to academic tasks.

Instruction in the use of cognitive strategies to solve problems is based on the assumption that students would learn to apply them to academic areas. This method is similar to one designed by Reuben Feuerstein called Instrumental Enrichment (Feuerstein, 1980). Instrumental Enrichment curriculum provides remediation of cognitive difficulties that may arise in any of three levels of information processing (input, elaboration, or output) through teacher mediation. For example, on any of the fifteen instruments in this program, a teacher first asks a series of key questions designed to elicit both a definition of the problem and potential strategies for solving it. Next, the teacher leads a discussion of what strategies worked best after the students attempted to solve the problem. Finally, the teacher helps the students formulate 
a general metacognitive principle based on their learning experience that applies that principle to other experiences in their own lives. Buser and Reimer (1988) developed another program designed to teach cognitive strategies through logical problem solving using practical life experiences of the students. The program facilitates the transfer of strategy usage to the academic setting by incorporating the strategies into existing curricula. The five-step process of instruction includes discovery activities, discussion, conclusion, follow-up activities, and integration. In instructional methods such as Instrumental Enrichment or the five-step process of strategy training, the objective is for students to acquire cognitive strategies useful for future learning.

Cognitive strategies can also be taught to learning disabled students directly in academic subjects. Strategies such as verbal rehearsal, visual imagery, self-questioning, and categorization have been successfully used to help reading comprehension. Instruction in verbal rehearsal strategies has been used to reduce writing reversals and a step spelling study strategy has been successfully taught to learning disabled students to improve their ability to remember spelling words. Similarly, verbal labeling and self-questioning strategies have been found to be effective in helping learning disabled children solve mathematical problems. After learning cognitive strategies that can be 
used to approach specific reading, writing, or mathematical problems, learning disabled students could apply them to other problems within each academic area. Thus, it would be the generalization of these strategies as they apply to the academic subjects that would allow a learning disabled student to achieve more adequately in the mainstream.

Implications for Research

The findings of this study suggest the need for more extensive research into the use of cognitive strategies by learning disabled students to achieve success in the mainstream. Future research should work towards reducing the confounding variables in the present study and should be directed towards determining if learning disabled students are more likely to succeed in the mainstream after they have received instruction in the use of cognitive strategies.

This study used 10 students in each of the two groups that were examined. Thus, a larger population of learning disabled students in a Resource Specialist Program compared with students who had been released from a Resource Specialist Program would improve the reliability of the reported response patterns in the study. Additionally, the learning disabled student's use of cognitive strategies on Hagen's Central Recall Task should be studied across varied age and cognitive development levels. Students at particular stages of development differ in their ability to 
succeed on Hagen's Central Recall Task and in the use of cognitive strategies to aid recall (Tarver et al., 1976). It would be advantageous to determine the ages during which students begin to use cognitive strategies independently and when students are most receptive to cognitive strategy instruction. The present study also did not distinguish between the kinds of learners within the groups of NRSP and RSP students. For example, auditory learners in each group may have been more likely to use a verbal labeling or rehearsal strategy to help them recall the animal card in the series of seven cards. Visual learners may have been more likely to use a visualization strategy to aid recall. Posttest questioning in the present study revealed that more students in the NRSP group used cognitive strategies on Hagen's Central Recall Task than did students in the RSP group. The strategies used most often by students in the NRSP group were verbally oriented. It is possible that there were more students in the NRSP group who were auditory learners and Hagen's Central Learning Task may have been easier for such learners to complete successfully. Subsequent research should take into account the type of learners in the groups that are to be examined. Parallel studies that use tests other than Hagen's Central Learning Task to assess strategies should be conducted. This study used students' correct response patterns on Hagen's Central Learning Task and direct 
questioning to determine if cognitive strategies had been employed. Tests that more directly measure the use of cognitive strategies would enhance the validity of the study. Similarly, tests that are designed to measure cognitive strategies other than those that aid recall would promote a greater understanding of how the students in RSP and NRSP groups approach learning situations.

Future research should also fccus on the results of cognitive strategy instruction over time. The primary objective of such studies would be to determine if learning disabled students are more likely to function independently in the mainstream after cognitive strategy instruction in a Resource Specialist Program. Additionally, strategy instruction may be appropriate only for select subgroups of learning disabled students. Therefore, as new instructional approaches are developed, it should be determined if there is a subgroup for which the approaches may fit best. Correspondingly, it would be beneficial to compare two types of cognitive strategy instruction. The effects of teaching cognitive strategies through problem solving versus the direct application of strategies to academic subject areas should be reviewed. There may be a specific approach that best fits the means by which learning disabled students successfully acquire skills.

\section{Summary}

This study demonstrated that 12- to 13-year-old 
learning disabled students who had graduated from a Resource Specialist Program (NRSP) scored higher on Hagen's Central Learning Task, a selective attention activity requiring them to remember where an animal picture card was in a series of seven cards, than did 12- to 13-year-old learning disabled students who were currently enrolled in a Resource Specialist Program (RSP). Upon examination of proportion of correct choice responses at each position and responses to posttest questioning, it was determined that students in the NRSP group were more likely to use cognitive strategies to help them with recall than were students in the RSP group. The correct response pattern for the NRSP group indicated that they were more likely to remember the first animal that had been presented to them in the seven-card series. Previous research had labeled this phenomenon primacy effect and had concluded that. it revealed the use of a verbal rehearsal strategy by students in this group. Conversely, the response pattern for the RSP group indicated that they were more likely to remember the animal that they saw last in the seven-card series. Prior research had labeled this pattern recency effect and reported that it denoted a lack of cognitive strategy use. Posttest questions indicated that $80 \%$ of students in the NRSP group used a verbal, visual, or combination strategy to aid recall while $50 \%$ of the RSP group used a verbal or pictorial strategy. These results were applied to finding a qualitative difference 
between students in the NRSP group and students in the RSP group. Students in both groups were similar in age and intellectual potential. The primary difference between the two groups was that students in the NRSP group were able to achieve successfully in the mainstream of their schools without help from a resource specialist. Therefore, it was deduced that students in the NRSP group may have been able to use cognitive strategies efficiently to help them achieve. This deduction points toward the need for exploration into cognitive strategy instruction for learning disabled students. Future research will help to reduce confounding variables in the present study and determine the true value of instructing learning disabled students in the use of cognitive strategies. It may be an important means of providing learning disabled students with skills that they can use to achieve success in the mainstream. 
REFERENCES 
Belmont, J. M., \& Butterfield, E. C. (1971). What the development of short-term memory is. Human Development, $\underline{14}, 236-248$.

Brown, R. T., \& Alford, M. A. (1984). Ameliorating attentional deficits and concomitant academic deficiencies in learning disabled children through cognitive strategy - Journal of Learning Disabilities, $17,20-24$.

Brown, R. T., \& Quay, C. C. (1977). Reflectionimpulsivity in normal and behavior disordered children. Journal of Abnormal Child Psychiatry, 4 (5), 457-461. Buser, K. P., \& Reimer, D. (1988). Developing cognitive strategies through problem solving. Teaching Exceptional Children, 22-25.

Carpenter, T., Moser, J., \& Romburg, T. (1982). Addition and subtraction: A cognitive perspective. Hillsdale, NJ: Lawrence Erlbaum.

Clark, F. C., Deschler, D. D., Schumaker, J. B., \& Alley, G. R. (1984). Visual imagery and selfquestioning: Strategies to improve comprehension of written material. Journal of Learning Disabilities, $17(3), 145-152$.

Dawson, M. li., Hallahan, D. P., Reeve, R. E., \& Ball, D. W. (1980). The effect of reinforcement and verbal rehearsal on selective attention in learning disabled children. Journal of Abnormal Psychiatry, $8,133-144$. 
Deschler, D., Schumaker, J., \& LevY, B. (1984). Academic and cognitive intervention for learning disabled adolescents, Part $I$. Journal of Learning Disabilities, 17, 108-111.

Donaldson, M., \& Strang, H. (1969). Primacy effect in short-term memory in young children. Psychonomic Science, $16,59-60$.

Dykman, R. A., Ackerman, P. T., \& Oglesby, D. M. (1980). Correlates of problem solving in hyperactive, learning disabled, and control boys. Journal of Learning Disabilities, 13, 23-32.

Egeland, B. (1974). Training impulsive children in the use of more efficient scanning techniques. Child Development, $45,165-171$.

Ellis, N. R. (1970). Miemory processes in retardates and normals. In N. R. Ellis (Ed.), International review of research in mental retardation, Volume 4. New York:' Academic Press. Feuerstein, R. (1980). Instrumental enrichment: An intervention program for cognitive modifiability. Baltimore, MD: University Park Press. Graham, S., \& Freeman, S. (1985). Strategy training and teacher vs. student-controlled study conditions: Effect on LD students' spelling performance. Learning Disabilities Quarterly 8, 267-274. 
Hagan, J. W. (1967). The effect of distraction on selective attention. Child Development, 38, 685-694.

Haines, D. J., \& Torgeson, J. K. (I979). The effects of incentives on rehearsal and short-term memory in children with reading problems. Learning Disabilities Quarterly, $\underline{2}, 48-55$.

Hallahan, D. P., \& Reeve, R. E. (1980). Selective attention and distractibility. In B. K. Koegh (Ed.), Advances in special education, Vol. 1. Greenwich, CT: JAI Press. Hallahan, D. P., \& Sapona, R. (1983). Self-monitoring of attention and learning disabled children: Past research and current issues. Journal of Learning Disabilities, $16,616-620$.

Hallahan, D. P., Tarver, S. G., Kauffman, J. M., \& Graybeal, N. L. (1978). Selective attention abilities of learning disabled children under reinforcement and response cost. Journal of Learning Disabilities, 11, $430-438$.

Harth, R. (1982). The Feuerstein perspective on the modification of cognitive performance. Focus on Exceptional Children, 15, 1-12.

Heinicke, C. M. (1972). Learning disturbance in chiluhood. In B. J. Wolman (Ed.), Manual of child psychopathology. New York: Harper \& Row.

Howe, M. (1970). Introduction to human memory. New York: Harper \& Row. 
Johnson, D., \& Myklebust, H. (1967). Learning disabilities: Educational principals and practices. New York: Grune and stratton.

Kirk, S., \& Chalfant, J. (1984). Academic and developmental learning disabilities. Denver: Love Publishing. Koppitz, E. (1972-3). Special class pupils with learning disabilities: A five year follow up study. Academic Therapy, $8,133-139$.

Lerner, J. (1985). Learning disabilities. Boston, MA: Houghton, Mifflin Company. Maier, A. S. (1980). The effect of focusing on the cognitive processes of learning disabled children. Journal of Learning Disabilities, 13(3), 34-38. Mather, N., \& Healy, W. C. (1984). The efficacy of a memory strategy for eliminating reversal behavior. Journal of Learning Disabilities, $\underline{2}, 84-88$. Messerer, J., Hunt, E., Meyers, G., \& Lerner, J. (1984). Feuerstein's instrumental enrichment: A new approach for activating intellectual potential in learning disabled youth. Journal of Learning Disabilities, 17, 322-325. Piaget, J. (1970). The science of education of the psychology of the child. New York: Grossman. Resnick, L., \& Ford, W. (1981). The psychology of mathematics instruction. Hillsdale, NJ: Erlbaum Associates. 
Rose, M. C., Cudick, B. P., \& Higbee, L. L. (1983). Verbal rehearsal and visual imagery: Mneumonic aids for learning disabled children. Journal of Learning Disabilities, $16(5), 255-260$.

Schunk, D. H., \& Cox, P. D. (1986). Strategy training and attributional feedback with learning disabled students. Journal of Educational Psychology, 78(3), 201-209. Tarver, S. G., Hallahan, D. P., Cohen, S. B., \& Kauffman, J. M. (1977). The development of visual selective attention and verbal rehearsal in learning disabled boys. Journal of Learning Disabilities, 491-500.

Tarver, S. G., Hallahan, D. P., Kauffman, J. M., \& Ball, D. W. (1976). Verbal rehearsal and selective attention in children with learning disabilities: A developmental lag. Journal of Experimental Child Psychology, 22, $375-385$.

Torgeson, J. K. (1975). Problems and prospects in the study of learning disabilities. In M. Hetherington and J. Hagen (Eds.), Review of research in child development, Vol. 5. Chicago: University of Chicago Press. Torgeson, J. K. (1977a). The role of nonspecific factors in the task performance of learning disabled children: A theoretical assessment. Journal of Learning Disabilities, 10, 24-34. 
Torgeson, J. K. ( $1977 \mathrm{~b})$. Memorization processes in reading disabled children. Journal of Educational Psychology, $69,571-578$.

Torgeson, J. K. (1980). Conceptual and educational implications of the use of efficient task strategies by learning disabled children. Journal of Learning Disabilities, $13(7), 19-26$.

Torgeson, J. K., \& Houck, D. G. (1980). Processing deficiencies in children who perform poorly on the digit span test. Journal of Educational Psychology, $\underline{72}$, $141-160$.

Torgeson, J. K., \& Gioldman, T. (1977). Rehearsal and short-term memory in reading disabled children. Child Development, $48,56-60$.

Torgeson, J. K., Murphy, H. A., \& Ivey, C. (1979). The influence of an orienting task on the memory performance of children with reading problems. Journal of Learning Disabilities, 12, 396-401. Wong, B. Y. L. (1980). Activating the inactive learner: Use of questions/prompts to enhance comprehension and retention of implied information in learning disabled children. Learning Disabilities Quarterly, 3 , 29-37. Wong, B., Wong, R., \& Foth, D. (1977). Recall and clustering of verbal materials among normal and poor readers. Bulletin of Psychonomic Society, 10, 375-377. 
Ysseldyke, J. (1978). Remediation of ability deficits: Some major questions. In L. Mann, I. Goodman, \& J. Wiederholt (Eds.), Teaching the learning disabled adolescents. Boston: Houghton Mifflin. 